\title{
López Rider, J. (2020). Paisajes medievales en la campiña sur de Córdoba. Monografías de la Sociedad Española de Estudios Medievales. Serie Maior 13. Murcia: Sociedad Española de Estudios Medievales-Editum- CSIC. 416 pp. ISBN: 978-84-17865-69-6
}

Clara Almagro VidAL
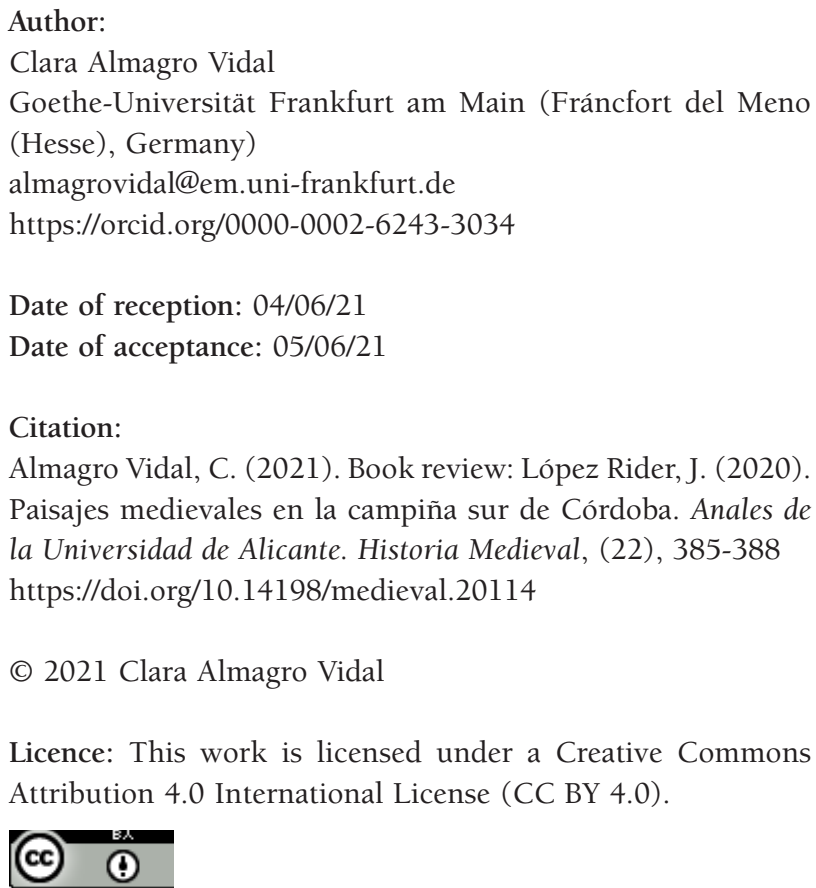

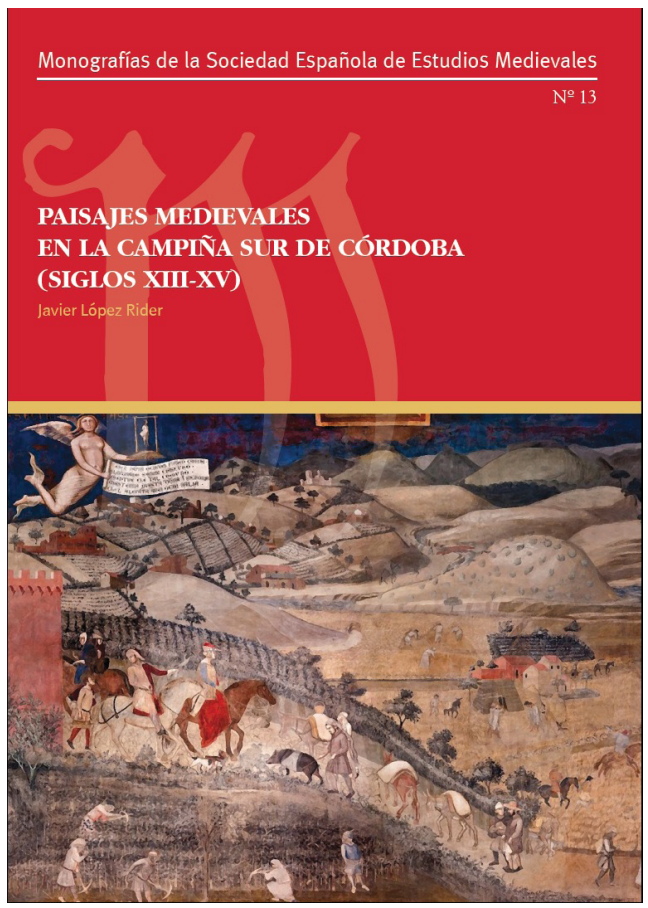

Los acontecimientos no se suceden en espacios carentes de características diferenciadoras. Los procesos históricos se producen en medios físicos que los determinan de manera fundamental y cuyo conocimiento contribuye de forma decisiva a explicarlos. La conciencia de las realidades físicas que acompañan al desarrollo histórico afortunadamente impregna cada vez más la labor de los historiadores. Esto ha llevado al desarrollo de nuevos análisis centrados en el territorio y en los paisajes como elemento no sólo explicativo de otros procesos sino de interés por sí mismos como objetos de estudio. Esta monografía constituye una estimable adición a la creciente literatura sobre este tema, planteando un innovador análisis sobre ciertos aspectos del paisaje. 
En esta monografía, Javier López Rider presenta los hallazgos de su investigación doctoral, la cual se centra en el estudio de la zona sudoeste de la actual provincia de Córdoba desde el momento de su conquista por los castellanos hasta el final de la Edad Media (siglos XIII-XV).

En particular, la investigación desarrollada por López Rider se centra en tres aspectos particulares de los paisajes medievales: las formas de poblamiento, la red parroquial y las estructuras castrales. La estructura del libro refleja los objetivos planteados por el autor en la introducción (p. 19): analizar el paisaje partiendo de las estructuras de poblamiento y aspectos asociados a ellas como elementos del paisaje. Para tal fin, la obra está dividida en dos grandes bloques. El primero está dedicado a proporcionar un marco para los hallazgos sobre los que se extiende en la segunda parte. De esta manera, la sección inicial del trabajo contiene una reflexión sobre el concepto de paisaje, justificando la selección de elementos en los cuales el autor centrará posteriormente su análisis. Asimismo, revisita la cuestión de si existió un libro de repartimiento para esta región, argumentando que las circunstancias que rodearon la conquista y sus momentos posteriores difícilmente posibilitarían la realización de este instrumento para la repoblación. Asimismo, se hace un recorrido por las distintas modalidades de asentamiento que aparecen en las fuentes escritas en cada momento y las características de cada una, partiendo de las de mayor entidad, como las villas, y llegando a entidades menores tales como los villares, los caseríos o las chozas). En su descripción, presta especial atención al número estimado de habitantes de cada uno, sus niveles de desarrollo desde un punto de vista administrativo y la categoría jurídica a ellos asignada.

A continuación, el autor desarrolla un análisis individual de las distintas entidades de poblamiento del área de estudio. Esta sección está dividida a su vez cuatro secciones: las dos principales están dedicadas a los núcleos que tuvieron continuidad en el tiempo ("núcleos permanentes") y a aquellos que no la tuvieron ("núcleos carentes de perdurabilidad"), respectivamente. La exploración de los casos que caían bajo estas dos categorías de análisis ocupan buena parte de la obra. El panorama de las estructuras de poblamiento se completa y complementa con un análisis de la red parroquial que aborda no solo las parroquias sino también formas asociadas al culto religioso sin tener el nivel de desarrollo que tenían las parroquias (mitaciones, limitaciones, ermitas), $-\mathrm{y}$ con un repaso de los elementos que articulaban la red castral del territorio (castillos, torres...).

La publicación incluye un juego de mapas de elaboración propia (dos de ellos desplegables) y una serie de ilustraciones que muestran las características físicas de los enclaves y hallazgos arqueológicos, así como otros elementos gráficos que resultan de gran utilidad para identificar y localizar los enclaves a los que se refiere el texto, relaciones espaciales y otros aspectos tratados en el análisis. La inclusión 
de este material gráfico, en este sentido, es acertada, pues complementa y refuerza el contenido del texto.

El acercamiento realizado por el autor al tema de estudio -las redes de poblamiento y su contribución a la construcción de paisajes- es apropiadamente sistemático y sus hallazgos están sólidamente fundamentados en fuentes. En su análisis, el autor integra con éxito la información contenida en la documentación escrita -resultado de un muy extenso y sistemático trabajo en archivos- e información arqueológica para rastrear la trayectoria de los distintos núcleos. Igualmente, la atención que presta a la toponimia y la tarea realizada para rastrear cambios de nombre, sus implicaciones y las dificultades que plantea para la investigación resulta enormemente interesante. Entre las aportaciones más destacadas de esta obra se encuentra sin duda la acertada aproximación que realiza a los procesos de despoblación y sus implicaciones. Su percepción de los asentamientos como entes vivos y cambiantes a lo largo del tiempo resulta enormemente acertada, al igual que la distinción que realiza entre la categoría jurídica de los núcleos de población y la existencia de los mismos como lugares habitados. Tal como muestra en numerosos ejemplos, en ocasiones se produce una divergencia entre ambos aspectos en muchos casos liminales de poblamiento que ha llevado a menudo a una inexacta interpretación de los testimonios contenidos en las fuentes. De este modo, el autor emplea el término "despoblados habitados" para hacer referencia a entes de población que desde un punto de vista físico y humano existían pero que no poseían suficiente entidad por sí mismos desde una perspectiva institucional, bien porque habían perdido contingentes poblacionales que les habían hecho perder su entidad e independencia, bien porque nunca la adquirieron. De manera similar a como otros investigadores han aplicado conceptos análogos (falsos despoblados, deraygados...) a otras regiones, la introducción de esta categoría explicativa al reino cordobés abre posibilidades para una interpretación más ajustada a la compleja realidad del poblamiento medieval. De esta manera, el resultado de aplicar este concepto contribuye a rectificar inexactas apreciaciones relacionadas con los procesos de despoblamiento -que corresponderían más bien con reorganización de los patrones de asentamiento.

Esos mismos matices en la interpretación son aplicados igualmente a la red parroquial, con las "iglesias despobladas" y otros tipos de entidades de menor categoría (mitaciones, limitaciones) que se mencionan en las fuentes medievales. Sea como elementos de referencia visual, como entidades propietarias de tierras y otros recursos, o como unidades de organización del territorio desde un punto de vista eclesiástico, el destino de estas estructuras eclesiásticas estuvo estrechamente relacionado con la evolución del poblamiento en sí.

Como es normal en un tema de investigación con la extensión y complejidad como el que aborda la presente obra, no todos los aspectos de los fenómenos pueden ser explorados con el mismo nivel de detalle, bien porque las fuentes no proporcio- 
nan información al respecto, bien por la necesaria selección de elementos de análisis que se debe llevar a cabo. En este sentido, un punto muy interesante que merecería mayor detenimiento es el destino que siguió la población musulmana que había asentada en este territorio antes de la conquista y cómo se produjo su sustitución por pobladores cristianos. El autor apunta de manera general la sublevación de 1264 como causa fundamental para el despoblamiento mudéjar (p. 102) y menciona la presencia musulmana puntualmente con anterioridad, así el peso que su herencia tuvo en la organización del reino cordobés tal como reflejan la toponimia y la red castral, entre otros aspectos. Estos mismos testimonios suscitan a su vez numerosas preguntas sobre cómo se produjeron los procesos de transición poblacional en cada caso y las implicaciones que éstos tuvieron para la organización del poblamiento y de estos territorios que esperamos puedan ser abordados en futuras investigaciones.

No cabe duda que la presente obra se convertirá en un trabajo de referencia y potencial modelo a seguir para futuras investigaciones sobre el Reino de Córdoba y sobre el poblamiento medieval. 